\title{
The synergistic effect of am and mo derived gel in burn and wound healing
}

\begin{abstract}
Burn is a major clinical concern in the developing and poor countries. Now-a-days the treatment of burn in an effective way is a great challenge. It has already been established that amniotic membrane and Moringa oleifera, a medicinal plant, are a great focus of interest for burn wound healing. Amniotic membrane is a natural gift which promotes faster wound healing in partial and superficial burn injury since 1910. It has prominent characteristics in the management of burn injury such as availability, economical concern, faster wound healing, pain reduction and provide protection from the infection. Furthermore, Moringa oleifera also promotes wound healing process, wound contraction and increases the rate of epithelialization due to their astringent and antimicrobial properties and the bioactive compound vicenin-2. As the burn healing process is time consuming, recently patients are suffering from the various difficulties such as slow epithelialization rate, poor dressing, staying in the hospital for long time. Therefore, the focus of this review is to explore the combined effects of amniotic membrane and Moringa oleifera for faster wound healing in the management of burn patient.
\end{abstract}

Keywords: Wound and burn injury; Amniotic membrane; Moringa oleifera; Combined effect; Faster healing
Volume II Issue I - 2018

\author{
Md Liakat Hossain,' Md Majharul Islam, ${ }^{2}$ \\ Farzana Diba,' Md Zahid Hasan,' SM \\ Asaduzzaman' \\ 'Institute of Tissue Banking and Biomaterial Research, Atomic \\ Energy Research Establishment, Savar, Bangladesh \\ ${ }^{2}$ Department of Biochemistry \& Molecular Biology, \\ Jahangirnagar University, Bangladesh \\ Correspondence: SM Asaduzzaman, Institute of \\ Tissue Banking and Biomaterial Research, Atomic Energy \\ Research Establishment, Savar, Dhaka- I349, Bangladesh, Tel \\ +8801726894690 , Fax +887790034, \\ Emailsikderasad@yahoo.com
}

Received: November 01, 2017 | Published: January 23, 2018
Abbreviations: AM, amniotic membrane; MO, Moringa oleifera; ITBBR, institute of tissue banking and biomaterial research; VEGF, vascular endothelial growth factor; HGF, hepatocyte growth factor; TGF, transforming growth factor; HLA, human leukocyte antigen; DR, differential regulation; MSC, mesenchymal stem cells; SLPI, secretary leukocyte proteinase inhibitor; AECS, amniotic epithelial cells; AMCS, amniotic mesenchymal cells

\section{Introduction}

Skin is the largest organ in body which comprises $15 \%$ of the body weight. It serves as a wall-like barrier that protects our body from the environmental microorganisms. ${ }^{1,2}$ Epidermal glands in the skin secrete substances which contribute to the preservation of water-electrolyte balance of the body and permit water vapor. It also regulates body temperature through neural feedback mechanism by operating the hypothalamus and is formed by two main layers, including epidermis covering the body surface and the dermis involving the connective tissue. ${ }^{3}$ Skin can be injured basically by two types of wounds: (i) open wounds where skin is torn, cut or punctured and (ii) closed wounds where blunt force trauma causes a contusion. Among various kinds of wounds, burn is considered one of the most severe wounds as they are susceptible to infections due to vascular necrotic tissue. Epidermal integrity loss in the skin structure is the foremost consequence of burn wound. Thermal, electrical and chemical injuries are the most common reasons of burn wounds. The severity of burn injuries is set according to the depth of skin involvement and the percentage of total body surface area. ${ }^{4}$ Skin burn wound is a fourth graded injury among all injuries. In spite of recent advances in burn wound treatment, scarring rate remains high and the deaths are over 180,000 each year throughout the world (WHO, 2017). ${ }^{5}$ Currently, burn death rates are decreasing in many high-income countries but the rate of child deaths from burns is over 7times higher in low- and middle-income countries. Since burns have become a global public health problem, to treat burn patients several anti-burn drugs are used. However, these drugs have many side effects and pose an economic burden to the patients. Therefore, scientists have turned to natural remedies, including human amniotic membrane (AM) and other wound healing plants. Among these plants Moringa oleifera (MO) is one of them which have many evidences on the wound healing activities. Although there have been many research activities on both AM and MO in burn wound healing, their combined effect has not been yet observed. If a gel combined with AM and MO leaves is prepared, the combined effect may be very beneficial for burn wound healing.

\section{Amniotic membrane}

The inner most lining of the human placenta that is normally discarded after parturition is amniotic membrane. It contains many growth factors, proteins and stem cell reserves that accelerate wound healing. The amnion is expanded and become the amniotic sac due to the amniotic fluid inside it which serves a protective environment for embryo development. It is the nearest thing to the epidermis and it is like an extension of the baby's skin that is formed by the ectoderm of the fetus. ${ }^{6}$

\section{Structure and composition of amniotic membrane}

Amniotic membranes develop from extra-embryonic tissue and consist of a foetal component (chorion and amnion) and a maternal component (deciduas) (Figure 1). These two parts are held together by the chorionic villi and connect the cytotrophoblastic shell of the chorionic sac to the decidua basalis. The foetal component separates the foetus from the endometrium. The amniochorionic membrane forms the outer limits of the sac that encloses the foetus, while the innermost layer of the sac is the AM. Thickness of normal AM is in between $0.02-0.05 \mathrm{~mm}^{7}$ From histological perspective, AM is an avascular, thin, tough transparent membrane. ${ }^{8}$ It is composed of three major layers: (i) epithelium, a single layer of metabolically active cuboidal and columnar cells which are in direct contact with amniotic 
fluid; (ii) basement membrane; (iii) and a mesenchymal layer., ${ }^{9,10}$ The mesenchymal layer is further divided into compact, fibroblast and spongy layer. AM contains two distinct types of cells with different embryonic origin: embryonic ectoderm derived amniotic epithelial cells (AECs) and mesoderm derived amniotic mesenchymal cells (AMCs). ${ }^{11,12}$

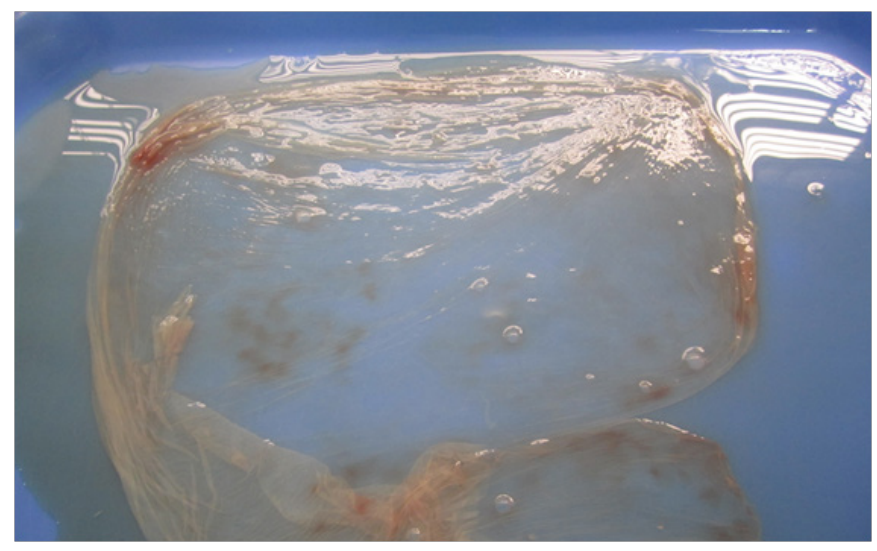

Figure I Amniotic membrane, Separation of amnion from chorion.

The major components that contribute to the integrity of AM and its biochemical properties are:

i. Cytoskeletal proteins of AM epithelial and stromal cells, e.g. actin, tubulin, different cytokeratins, vimentin, desmin;

ii. junctional proteins between AM epithelial cells, e.g. occludin, claudin-3and- 4 and desmoplakin and

iii. different types of collagen which are abundant in AM stroma e.g. Collagen-I, III, IV, V, VI, hyaluronan and proteoglycans. ${ }^{13}$ Cross section of the human amniotic membrane indicates the biochemical characteristics of the section (Figure 2)..$^{14}$

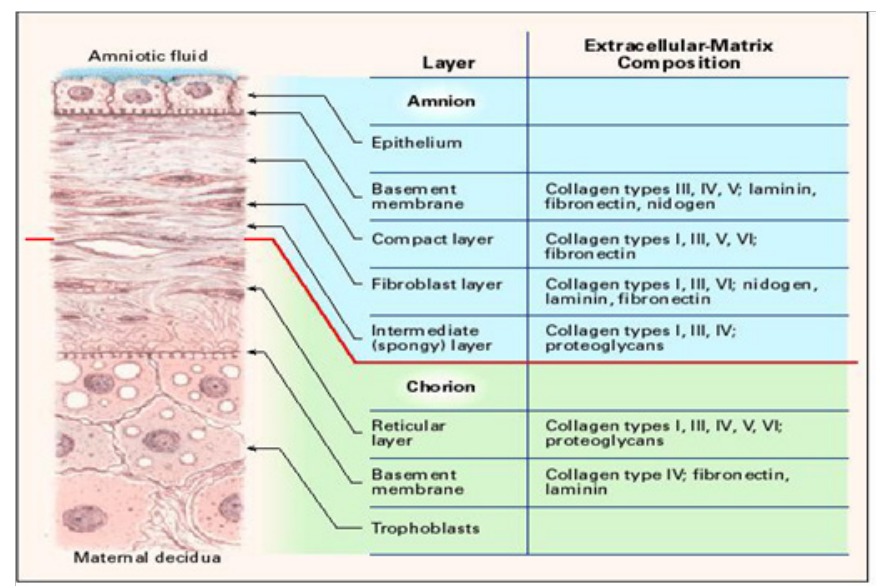

Figure 2 Cross section of the human amniotic membrane indicating the biochemical characteristics of the section. Adapted from Niknejad ${ }^{14}$ with permission.

\section{The role of amniotic membrane (AM) as a burn-dressing material}

Human amnion is used for centuries as a biological burn dressing material to treat superficial- and partial- thickness burns worldwide. ${ }^{15}$ An ideal wound dressing should be readily available, economical, easy to apply, able to provide good pain relief, able to protect the wound from infection, promote healing, prevent heat and fluid loss, elastic, adhere well to the wound, robust, able to withstand shear force, durable and non-antigenic, but multitudes of burn wound dressings available on the market are unable to meets all these demands. ${ }^{16} \mathrm{AM}$ is almost always discarded but satisfy most of the criteria for an ideal biological dressing. Its efficacy has been proved as a true biological burn dressing material and is readily available worldwide..$^{17,18}$ It is thin, elastic, adheres to the wound surface well, has effective vapor barrier, a durable cover for the raw surface, and a substantial pain reliever. ${ }^{19-21}$

\section{Clinical applications of amnion}

\section{Strong wound adherence property}

Amnion very firmly adheres to wound beds. Due to the fibrinelastin formation at the wound-dressing interface, the bonding between amnion and wound surface is biological, not mechanical. ${ }^{22}$

\section{No rejection phenomenon}

When the amnion is directly placed over the wound surface, it can fulfill some of the functions of the skin that are destroyed in burn injuries. As AM derived from the fetal ectoderm, it has the advantages of fetal skin allograft; furthermore, it is different from skin allograft and does not occur vascularization and rejection of the membrane. ${ }^{20,23}$ Human amniotic epithelial cells have lower inflammatory response and lack of rejection during allograft because they are unable to present human leukocyte antigen (HLA) A, B, C and DR surface antigens and beta-2-microglobulin. ${ }^{24}$ Specially the sterilized, freeze-dried AM is biocompatible and retains most of the physical, biological, and morphologic characteristics, so it is a useful biomaterial (Figure 3).

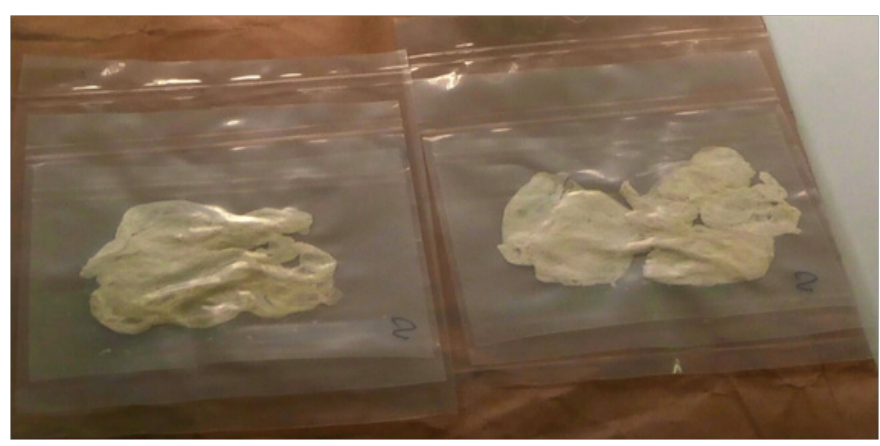

Figure 3 Freezed dried (lyophilized) irradiated amniotic membrane.

\section{Antimicrobial and antiviral properties}

AM seals the wound and prevents contamination via fibrin and elastin linkages. ${ }^{25}$ This tight bonding protects circulating phagocytes and allows faster removal of surface debris and bacteria from the wound. ${ }^{19}$ The mesenchymal stem cells (MSC) in AM show its antimicrobial activity in two ways: directly via the secretion of antimicrobial factors such as LL-37 and indirectly via the secretion of immunomodulative factors which upregulates bacterial killing and phagocytosis by immune cells. ${ }^{26,27}$ It also carries many bactericidal products of purine metabolism and lysozyme including defensins, elafin and secretary leukocyte proteinase inhibitor (SLPI) which act as a component of the innate immune system to provide protection from infection. Fetal skin and AM abundantly contain Cystatin E, which acts as a powerful antiviral agent. ${ }^{28}$ The mechanism of accelerated wound healing by amnion membrane is shown below (Figure 4). ${ }^{29}$ 


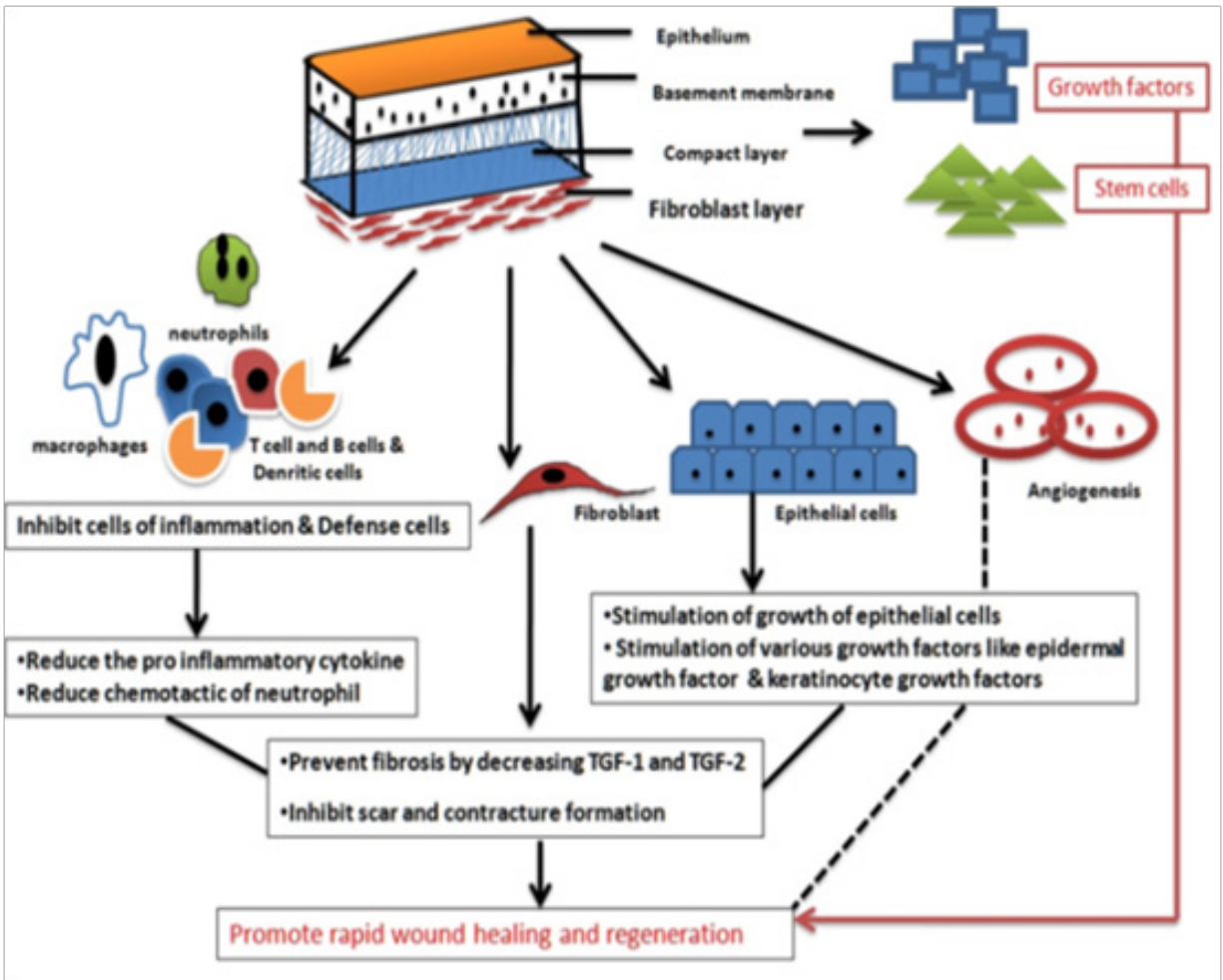

Figure 4 The wound healing mechanism by amniotic membrane. Adapted from Chopra. ${ }^{29}$

\section{Anti-scarring}

AM prevents scarring by secreting endothelial growth factor (VEGF), hepatocyte growth factor (HGF) which help to keep balance between TGF-1 and TGF-3 and down-regulate TGF-beta. It also modulates wound healing by tissue reconstruction ${ }^{29,30}$ and prevents pathological remodeling and excessive fibrosis by suppressing various immune cells such as T cell, dendritic cell and B cell. ${ }^{30}$

\section{Pain reduction}

AM alleviates pain by diminishing inflammation as well as providing better state of hydration that appease the wound bed to promote faster wound. Application of amnion to burn surfaces can protect the exposed nerve endings from external irritants that helps to decrease pain sensation by preventing nerve stimuli and thus AM reduces the pain score in adults and quieted a distressed child. ${ }^{29,30}$

\section{Minimizing fluid/water loss}

The amnion is composed of five distinctive layers namely epithelial, basement membrane, connective tissue, fibroblasts and a spongy layer. This structure resembles the stratum corneum which is a natural vapor barrier. ${ }^{14}$ The vapor barrier of AM reduces the amount of fluid loss by preventing excessive evaporation from the wound surface directly. ${ }^{31}$ However, it is noted that the membrane does not influence the fluid shift from the plasma into the interstitial compartment in the extracellular space. A study conducted by pigeon reported the beneficial role in the early treatment of burns to prevent fluid or plasma leakage. ${ }^{6}$

\section{Less frequent dressing and faster wound healing}

In a comparative study between amniotic membrane and silver sulfadiazine in second degree burn treatment, Mostaque and Rahman showed that the amniotic membrane is a better treatment option because its use reduces the length of hospital stay and the number of required dressing changes. Because of faster epithelialization it is easy and comfortable both for the doctor and patients. ${ }^{32,33}$ Amnion speeds up the epithelialization process, which results in faster wound healing in superficial and partial-thickness burns (with minimal oozing, and healing occurs without the need for auto-grafting) and superior to both allograft and xenograft materials. ${ }^{20,34}$ By accelerating the migration of fibroblasts and the development of collagen, amniotic membrane promotes healing during the first 6-8days of repair. ${ }^{34-36}$

\section{Neovascularization}

The most remarkable effect of amnion is the development of new vessels and it was observed grossly, histopathologically and immunohistologically. ${ }^{37}$ Increased vascularity in the AM-treated burn wound was noted microscopically. ${ }^{38}$ The proteins produced by amniotic epithelial cells have angiogenic effects. ${ }^{39}$

\section{Moringa oleifera (MO): another wound healing agent}

MO is commonly known as drumstick tree which belongs to the family of Moringaceae (Figure 5). It is native in India, Pakistan, Afghanistan, Bangladesh as well and now-a-days, it has been distributed in many countries of tropics and subtropics. It is a miracle tree because it has outstanding medicinal properties including wound healing, anti-tumor, anti-hepatotoxic, anti-fertility, hypotensive, diuretic, anti-ulcer, cardiovascular anti-cancer properties. ${ }^{40-42}$

\section{Medicinal properties}

Almost every parts of this plant used for various indigenous medicine elements. Because of its chemical constituents and amazing clinical uses (Table 1) ${ }^{40}$ it has recently been accepted as a demanding medicine. ${ }^{43}$ 


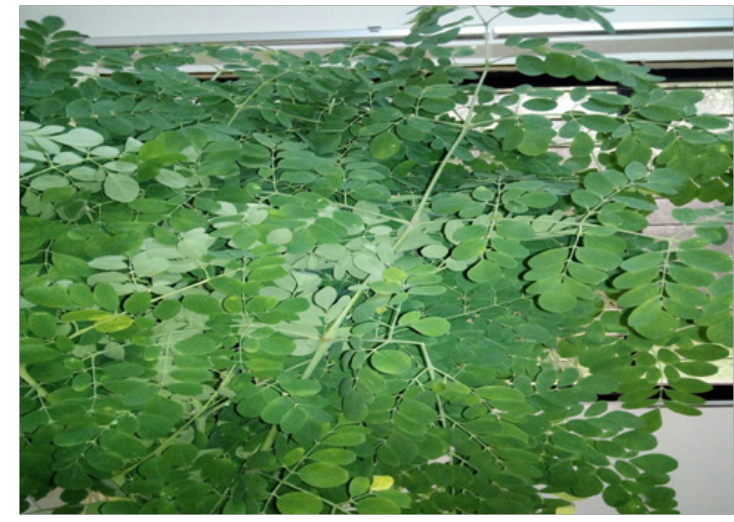

Figure 5 Moringa oleifera leaves.

\section{Wound healing mechanism of Moringa oleifera leaves extract}

Different complex processes such as inflammation, epithelialization, angiogenesis, granulation, tissue formation and the deposition of interstitial matrix are involved for tissue repair and wound healing. ${ }^{44}$ Microorganisms, especially bacteria (S. aureus and $P$. aeruginosa) are responsible for inflammatory response in both acute and chronic wounds and delay the wound healing process. The aqueous fraction of MO leaves contains some phytochemical compounds such as alkaloids, triterpenoids, tannins, and flavonoids. These metabolites possess compounds that play active role in wound healing and inhibits microbial growth by binding with DNA of the microorganisms. Flavonoids and tannins improve wound healing through its antioxidant activity and protect tissues against oxidative damage. ${ }^{4-47}$ The astringent and antimicrobial properties of MO leaves promote the wound healing process, wound contraction and increased rate of epithelialization. ${ }^{48}$ Furthermore, the methanolic crude extract and aqueous fraction of $\mathrm{MO}$ contain some bioactive compounds such as; kaempferol, quercetin and vicenin-2. These bioactive compounds are used in the drug discovery and development of wound healing agent that may enhance wound healing. ${ }^{49}$ The wound healing mechanism of aqueous fraction of Moringa oleifera is shown below (Figure 6). ${ }^{50}$

Table I Chemical constituents and clinical uses of Moringa oleifera

\begin{tabular}{lll}
\hline Plant part & Chemical constituents & Use \\
\hline & Benzyl iso thiocynate, nlazimicin, benzyl glycolsinolate Anti-oxidant & Anti-microbial anti-bactirial \\
Leaves & 4-(rhamnosylozybenzy) o-methylThio carbamate. Niazinnin A, B; Niazimicin. & Anti-atherosclerotic \\
& rhamnosloxy) benzyl] isothiocyanate,4-[(3'-O-acetyl-alphai-rhamnosyloxy)benzyl] & Anti-ulcer \\
& isothiocyanate and S-methyl-N $\{4-[($ alpha-l-rhamnosyloxy) benzyl]\} thiocarbamate & Anti-inflammatory \\
& Poly phenols like auertin n-3-glycoside rutin, Kaempferol & Anti-diabetic \\
Leaves, Seeds, & Quercetine, Kaempferol & Anti-oxidant \\
Roots & Poly phenols & Luoncil healing \\
\hline
\end{tabular}



Figure 6 Possible mechanism of aqueous fraction of Moringa oleifera in wound healing. Adapted from Muhammad ${ }^{50}$ with permission.

\section{Previous reports on the effect of amniotic membrane used with other substances}

Several epidemiological studies using animal models have shown that the combined effect of AM is more effective in burn and wound healing. Yifeng K et al. ${ }^{51}$ conducted a study with 200 rats and generated corneal alkali burn in the right eye of each rat and reported that (elaboration of MSC) MSCs and polysaccharide treatments significantly enhanced the recovery of corneal epithelium; the combination of polysaccharide-MSCs (PM) groups showed additive effects compared with single treatment groups. ${ }^{51}$

In another study, Patil SD and Rasika J reported the antimicrobial activity of MO with Cleome viscosa. This study was carried out against five pathogenic bacteria where the combination of MO and Cleome viscosa exerted strong synergistic effect towards $K$. pneumonia, $E$. coli, S. pneumoniae and S. aureus compared to the single treatment. ${ }^{52}$ Therefore, they speculated that the combined chemicals may give strong synergistic effect compare to the effect of the single one.

\section{Discussion}

Burn injury is one of the most devastating phenomena in the world. Humans have known the tragedy of severe burn injuries since the ancient time. It is the most common traumas in the developing countries and most burn injuries consume large amount of medical resources. But it is hardly possible to bear the enormous cost for the people with lower socio-economic classes. So it is important to find an appropriate material for dressing of burn wounds that improves healing and is readily available, easily applicable, economical, protective from infection and desiccation, and facilitates healing. ${ }^{53}$ Both AM and MO fulfil the above criteria. AM is being widely used as burn wound healing material worldwide and known as an ideal biological burn wound dressing material. ${ }^{17,18,23}$ Besides, MO is such a plant that all the parts of this plant e.g. leaf, blooms, root, bark, gum, seed and seed oil have been used for different ailments as a part of the indigenous medication of South Asia, including the treatment of inflammation and infectious diseases. ${ }^{54-56}$ Its leaves contain different type of compounds, for example, flavonoids, ascorbic acid, phenolics and carotenoids which are good source of natural antioxidant. ${ }^{57}$ These phenols have multiple beneficial biological effects including antioxidant activity, anti-inflammatory action, inhibition of platelet aggregation, antimicrobial activities and anti-tumor activities. ${ }^{58}$ 
It has huge quantities of proteins (20-29\%), vitamins and minerals which play vital role in the defense mechanisms and ultimate wound healing. ${ }^{59-61}$ The aqueous extract of MO has wound repairing property in male Swiss albino mice. Rathi BS et al. ${ }^{62}$ conducted a study with albino rats and observed a significant increase in the reduction of scar and percent wound contraction was reduced that indicated to the healing properties of the aqueous extract of Moringa oleifera leaves. ${ }^{62}$ A study conducted by Hukkeri VI and his group described antipyretic and wound healing properties of the ethyl acetate and ethanolic extracts of MO leaves. ${ }^{63}$ Significant antipyretic activity is observed in rats due to the ethanolic and ethyl acetate extracts of seeds where ethyl acetate extract of dried leaves shows wound healing activity $(10 \%$ extracts in the form of ointment) on excision, incision and dead space (granuloma). After all, bioactive fraction of MO shows antimicrobial, anti-fungal activities and vicenin- 2 compound enhances faster wound healing. ${ }^{49}$

\section{Conclusion and future perspectives}

In our study we found that both AM and MO are crucial agents for faster wound healing, better epithelialization, no rejection phenomena, less patients suffering and more importantly economical for poor patients. Since, freeze dried irradiated amniotic membrane and irradiated powdered Moringa oleifera leaves have no antigenicity, a gel combined with them could have used to speed up burn wound healing with cheaper rate. If it is possible, it might be a new frontier for burn patients specially those are very poor. In our following study the extensive research works will be performed to evaluate the combined effects of AM and MO derived gel, expecting more effectivity and beneficial role in the wound and burn healing.

\section{Authors' contributions}

Md. Liakat Hossain carried out study design, literature citing, table and figure collection, editing and manuscript writing. Md Majharul Islam helped to conduct literature citing, table and figure collection and manuscript writing. Farzana Diba contributed to literature citing and manuscript reading. Md. Zahid Hasan designed study and participated in helping to edit, revise and approve the final manuscript. S. M. Asaduzzaman supervised the writing of the manuscript and revised it critically for important intellectual content. All authors read and approved the final manuscript.

\section{Acknowledgements}

I would like to extend my sincere thanks to all authors who collaborate this work. The current study was derived from an MSC thesis conducted by me.

\section{Conflict of interest}

The authors declare that there is no conflict of interest.

\section{References}

1. Marks R. The stratum corneum barrier: the final frontier. $J$ Nutr 2004;134(8 Suppl):2017S-2021S.

2. Lee SH, Jeong SK, Ahn SK. An update of the defensive barrier functions of skin. Yonsei Med J. 2006;47(3):293-306.

3. Odland GF. Structure of the skin. In: Goldsmith LA, editor. Physiology, biochemistry and molecular biology of the skin. New York: Oxford University Press; 1991:3-62.

4. Tehrani S, Lotfi P, Tehrani S, et al. Healing Effect of Sesame Ointment on Second Degree Burn Wound in Rats. GMJ. 2016;5:56-62.
5. World Health Organization (WHO). Burns - fact sheet. World Health Organization technical report series. Geneva; 2017.

6. Pigeon J. Treatment of second-degree burns with amniotic membranes. Can Med Assoc J. 1960;83:844-845.

7. Malhotra C, Jain AK. Human amniotic membrane transplantation: Different modalities of its use in ophthalmology. World J Transplant 2014;4(2):111-121.

8. Agarwal A, Shankar S, Singh G, et al. Pleiotropic Properties of Amniotic Membrane for Modulation of Periodontal Healing. Int J Dent Med Res. 2014;1:110-117.

9. Parolini O, Alviano F, Bagnara GP, et al. Concise review: isolation and characterization of cells from human term placenta: outcome of the first international Workshop on Placenta Derived Stem Cells. Stem Cells. 2008;26(2):300-311.

10. Ilancheran S, Moodley Y, Manuelpillai U. Human fetal membranes: a source of stem cells for tissue regeneration and repair? Placenta. 2009;30:2-10.

11. Benirschke K, Kaufman P. Pathology of the human placenta. 5th ed. New York: Springer-Verlag. 2000.

12. Blackburn S. Maternal, Fetal and Neonatal Physiology: a clinical prospective. 5th ed. Australia: an imprint of Elsevier Science, Saunders; 2013.

13. Cirman T, Beltram M, Schollmayer P, et al. Amniotic membrane properties and current practice of amniotic membrane use in ophthalmology in Slovenia. Cell and tissue banking. 2014;15(2):177-192.

14. Niknejad H, Peirovi H, Jorjani M, et al. Properties of the amniotic membrane for potential use in tissue engineering. Eur Cell Mater. 2008;15:88-99.

15. Subrahmanyam M. Amniotic membrane as a cover for microskin grafts. Br J Plast Surg. 1995;48(7):477-478.

16. Halim AS, Khoo TL, Yussof SJM. Biologic and synthetic skin substitutes: an overview. Indian J PlastSurg. 2010;43(Suppl):S23-S28.

17. Trelford J, Trelford-Sauder M. The amnion in surgery, past and present. Am J Obstet Gynecol. 1979;134(7):833-845.

18. Matthews R, Faulk W, Bennett J. A review of the role of amniotic membranes in surgical practice. Obstet Gynecol Ann. 1982;11:31-58.

19. Rao TV, Chandrasekharam V. Use of dry human bovine amnion as a biological dressing. Arch Surg. 1981;116(7):891-896.

20. Colocho G, Graham WP, Greene AE, et al. Human amniotic membrane as a physiologic wound dressing. Arch Surg. 1974;109(3):370-373.

21. Talmi Y, Finkelstein Y, Zohar Y. Use of human amniotic membrane as a biologic dressing. Eur J Plast Surg. 1990;13(4):160-162.

22. Burleson R, Eiseman B. Nature of the bond between partial-thickness skin and wound granulations. Surgery. 1972;72(2):315-322.

23. Burleson R, Eiseman B. Mechanisms of antibacterial effect of biologic dressings. Ann Surg. 1973;177(2):181-186.

24. Akle CA, Adinolfi M, Welsh KI, et al. Immunogenicity of human amniotic epithelial cells after transplantation into volunteers. Lancet. 1981;2(8254):1003-1005.

25. Walker AB, Cooney DR, Allen JE. Use of fresh amnion as burn dressing. J Pediatr Surg. 1977;12(3):391-395.

26. Krasnodembskaya A, Song Y, Fang X, et al. Antibacterial effect of human mesenchymal stem cells is mediated in part from secretion of the antimicrobial peptide LL-37. Stem cells. 2010;28(12):2229-2238.

27. Talmi YP, Sigler L, Inge E, et al. Antibacterial properties of human amniotic membranes. Placenta. 1991;12(3):285-288. 
28. King AE, Paltoo A, Kelly RW, et al. Expression of natural antimicrobials by human placenta and fetal membranes. Placenta. 2007;28(2-3):161-169.

29. Chopra A, Thomas BS. Amniotic membrane: A novel material for regeneration and repair.J Biomim Biomater Tissue Eng. 2013;18:106-113.

30. Mishra S, Singh S. Human amniotic membrane: Can it be a ray of hope in periodontal regeneration? Indian J Res. 2014;3(9):118-121.

31. Gump F, Kinney J. Caloric and fluid losses through the burn wound. Surg Clin N Am. 1970;50(6):1235-1248.

32. Ravishanker R, Bath A, Roy R. "Amnion Bank" - the use of long term glycerol preserved amniotic membranes in the management of superficial and superficial partial thickness burns. Burns. 2003;29(4):369-374.

33. Mostaque A, Rahman K. Comparisons of the effects of biological membrane (amnion) and silver sulfadiazine in the management of burn wounds in children. J Burn Care Res. 2011;32(2):200-209.

34. Sharma SC, Bagree MM, Bhat AL, et al. Amniotic membrane is an effective burn dressing material. The Japanese journal of surgery. 1985;15(2):140-143.

35. Bose B. Burn wound dressing with human amniotic membrane. Ann $R$ Coll Surg Engl. 1979;61(6):444-447.

36. Bapat C, Kothary P. Preliminary report on acceleration of wound healing by amnion membrane graft. Indian J Med Res. 1974;62(9):1342-1346.

37. Faulk WP, Matthews R, Stevens PJ, et al. Human amnion as an adjunct in wound healing. Lancet. 1980;1(8179):1156-1158.

38. Kirschbaum S, Hernandez H. Use of amnion in extensive burns. In: $3 r d$ International Congress in Plastic Surgery. Excerpta Medica. Amsterdam; 1963. p. 152-162.

39. Burgos H, Sergeant R. Lyophilized human amniotic membranes used in reconstruction of the ear. JR Soc Med. 1983;76(5):433.

40. Spandana U, Srikanth P, Gopichand J, et al. A Review on Meracle tree: Moringa oleifera. J Pharmacogn Phytochem. 2016;5(6):189-191.

41. Sharma V, Paliwal R, Pracheta, et al. Phytochemical analysis and evaluation of antioxidant activities of hydro-ethanolic extract of Moringa oleifera Lam. Pods. J Pharm Res. 2011;4(2):554-557.

42. Chaudhary K, Chaurasia S. Neutraceutical properties of Moringa oleifera: a review. Eur J Pharm Med Res. 2017;4(4):646-655.

43. Gothai S, ArulselvanP, Tan WS, et al. Wound healing properties of ethyl acetate fraction of Moringa oleifera in normal human dermal fibroblasts. $J$ Intercult Ethnopharmacol. 2016;5(1):1-6.

44. Liu H, Lin S, Xiao D, et al. Evaluation of wound healing potential of resina draconis (Dracaena cochinchinensis) in animal models. Evid Based Complement Alternat Med. 2013:1-10.

45. Saurez J, Herreta MD, Marhuenda E. Hesperidine and neohesperidine dihydrochalcone on different experimental models of induced gastric ulcer. Phytother Res. 1996;10(7):616-618.

46. Ambia S, Narayana R, Gowri D, et al. Evaluation of wound healing activity of flavonoids from Ipomeacarnea Jacq. Anc Sci Life. 2007;26(3):45-51.

47. Kanchanapoom T, Kamel MS, Picheansoonthon C, et al. Hydrolyzable tannins and phenylpropanoid from Rafflesiakerrii Meijer (Rafflesiaceae) J Nat Med. 2007;61(4):478-479.
48. Muhammad AA, Arulselvan P, Karthivashan G, et al. In vitro antioxidant properties of bioactive fraction of Moringa oleifera. J Nat Prod Biomed Res. 2015;1:51-56.

49. Abubakar A, Muhammad NA, Pauzi S, et al. "In vitro wound healing potential and identification of Bioactive Compounds form Moringa oleifera Lam". Biomed Research Int. 2013;213:726-731.

50. Muhammad AA, Arulselvan P, Cheah PS, et al. Evaluation of wound healing properties of bioactive aqueous fraction from Moringa oleifera lam on experimentally induced diabetic animal model. Drug Des Devel Ther. 2016;10:1715-1730.

51. Yifeng K, Yixiang W, Xuan C, et al. Polysaccharide Hydrogel Combined with Mesenchymal Stem Cells Promotes the Healing of Corneal Alkali Burn in Rats. PLoS ONE. 2015;10(3):1-18.

52. Patil SD, Jane R. Antimicrobial activity of Moringa oleifera and its synergism with Cleome viscosa. Int J Life Sciences. 2013;1(3):182-189.

53. Mohammadi AA, Sabet B, Riazi H, et al. Human amniotic membrane dressing: an excellent method for outpatient management of burn wounds. Iran J Med Sci. 2009;34(1):61-64.

54. Singh KK, Kumar K. Ethnotherapeutics of some medicinal plants used as antipyretic agent among the tribals of India. J Econ Taxon Bot. 1999;23(1):135-141.

55. Morimitsu Y, Hayashi K, Nakagama Y, et al. Antiplatelet and anticancer isothiocyanates in Japanese horseradish, wasabi. Mech Ageing Dev. 2000;116(2-3):125-134.

56. Siddhuraju P, Becker K. Antioxidant properties of various solvent extracts of total phenolic constituents from three different agroclimatic origins of drumstick tree (Moringa oleifera Lam). J. Agric. Food Chem. 2003;51(8):2144-2155.

57. Dillard CJ, German JB. Phytochemicals: nutraceuticals and human health: A review. J Sci Food Agric. 2000;80(12):1744-1756.

58. Thurber MD, Fahey JW. Adoption of Moringa oleifera to combat undernutrition viewed through the lens of the "Diffusion of Innovations" theory. Ecol Food Nutr. 2009;48(3):212-225.

59. Olugbemi TS, Mutayoba SK, Lekule FP. Effect of Moringa (Moringa oleifera) inclusion in Cassa based diets fed to broiler chickens. Int J Poult Sci. 2010;9(4):363-367.

60. Abou-Elezz FMK, Sarmiento-Franco L, Santos-Ricalde R, et al. Healthful impacts of dietary consideration of Leucaena leucocephala and Moringa oleifera leaf meal on Rhode Island Red hens se performance. CUBAN J AGR SCI. 2011;45:163-169.

61. Moyo B, Masika PJ, Hugo A, et al. Nutritional characterization of Moringa (Moringa oleifera Lam.) leaves. Afr J Biotechnol. 2011;10(60):12925-12933.

62. Rathi BS, Bodhankar SL, Baheti AM. Evaluation of aqueous leaves extract of Moringa oleifera Linn for wound healing in albino rats. Indian J Exp Biol. 2006;44(11):898-901.

63. Hukkeri VI, Nagathan CV, Karadi RV, et al. Antipyretic and wound healing activities of moringa oleifera lam. in rats. Indian J Pharm Sci. 2006;68:124-126. 